\title{
The Formalization of the Business Process Modeling Goals
}

\author{
Ligita Bušinska and Mārīte Kirikova \\ Institute of Applied Computer Systems, Riga Technical University, Kalı̣u iela 1, Riga, \\ LV-1658, Latvia \\ \{ligita.businska, marite.kirikova\}@rtu.lv
}

\begin{abstract}
In business process modeling the de facto standard BPMN has emerged. However, the applications of this notation have many subsets of elements and various extensions. Also, BPMN still coincides with many other modeling languages, forming a large set of available options for business process modeling languages and dialects. While, in general, the goal of modelers is a central notion in the choice of modeling languages and notations, in most researches that propose guidelines, techniques, and methods for business process modeling language evaluation and/or selection, the business process modeling goal is not formalized and not transparently taken into account. To overcome this gap, and to explicate and help to handle business process modeling complexity, the approach to formalize the business process modeling goal, and the supporting three dimensional business process modeling framework, are proposed.
\end{abstract}

Keywords: Business process modeling, business process language, business process modeling goal, business process modeling framework.

\section{Introduction}

Nowadays business process modeling application areas are rapidly expanding [1]. As a result, enterprises are faced with a situation where the same business processes are modeled for different purposes [2]. On the other hand, a number of the studies [3], [4], [5], [6], [7], [8], [9] indicate that particular business process modeling languages are appropriate for certain business process modeling goals. The question arises, how to find a modeling language that is suitable for a certain modeling goal. The selected modeling language must have appropriate modeling constructs for representing a business process from a certain perspective, as well as making it possible to model a business process with a certain degree of precision and formalization according to the required level of abstraction. Interdependencies between the business process, modeling goal, and modeling language can be represented in the form of a triangle (Figure 1).

Looking at different researches that propose guidelines, techniques, and methods for business process modeling language evaluation and/or selection, one can conclude that the business process modeling goal is not formalized and is not taken into account transparently when selecting the modeling language. The modeler him or herself has to decide what characteristics of the modeling language are more suitable for a particular modeling purpose, or the authors offer a certain modeling language for certain modeling tasks without evaluation of possible alternatives.

The paper proposes how to formalize the business process modeling goal by specifying parameters for specific levels of business process abstraction. As a result, business process modeling languages can be evaluated according to the values of parameters of specific business 
process modeling goals. In order to identify the values of the parameters, the paper uses a multilevel Business Process Modeling Framework.

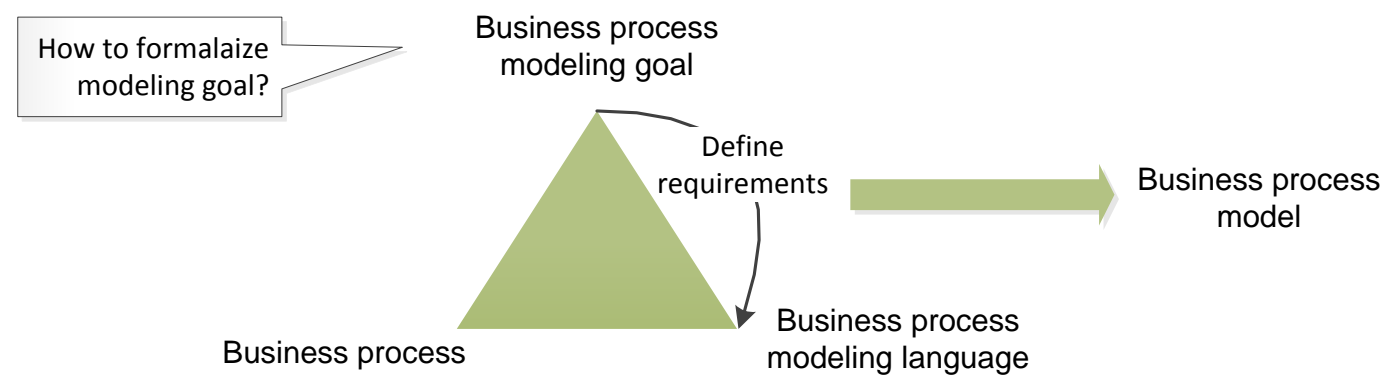

Figure 1. Interdependencies between a business process, modeling language, and modeling goal

The remainder of the paper is organized as follows. In Section 2 the related work is discussed. In Section 3 the grouping of business process modeling goals is proposed. In Section 4 the business process abstraction types are described. In Section 5 the proposed approach for formalization of business process modeling goal and supporting business process modeling framework are introduced. Section 6 illustrates how Business Process Modeling Framework could be used for specification of the modeling goal parameters. A brief conclusion is presented in Section 7.

\section{Related Work}

The guidelines, techniques, and methods for business process modeling language evaluation and/or selection proposed by different researches can be organized in several groups. One group of solutions, such as [10], [11], [12], [13], [14], offers to estimate business process modeling language characteristics. However, it is not explained there what are the characteristics that a modeling language has to have in order to be suitable for a particular modeling goal. Other researches offer to use particular business process modeling languages for certain modeling purposes (e.g., [4], [8], [9], [15]). However, the choice of the modeling language is mostly based on the author's subjective opinion. Another group of solutions (e.g., [16], [17], [18], [19]) offers to adapt business process model content to a new modeling purpose, using various techniques such as changing the level of granularity, reducing unnecessary details, or generalizing the content of the model. Finally, there are solutions that provide transformations between different abstraction levels [20], [21], [22], [23], [24], [25], for instance, the conceptual models are transformed to implementation models according to Model Driven Approach (MDA) [26]. Usually, each abstraction level is realized by a certain modeling language, and the choice of this language is not clarified.

The above described solutions for evaluation and/or selection of business process modeling languages differ in the way they take into account the modeling goal. In Table 1 it can be seen that many of the solutions do not provide the selection of the modeling language according to the modeling goal. Only one solution [27] offers a way to formalize the modeling goal. The authors of this solution propose initially to determine what real-world things should be modeled and then to estimate if modeling languages provide appropriate syntactical constructs to model such realworld things. This is achieved by defining the intersection of the modeling languages and modeling goal using the Bunge-Wand-Weber (BWW) ontology. However, in [27] only particular aspects of a business process modeling goal are considered, disregarding other characteristics such as the required degree of abstraction level, precision, and formalization degree. Additionally in [28] BWW ontology has been criticized, since it is designed at too high a level of abstraction, making it inefficient for detailed characterization of a modeling goal. 
Table 1. The solutions for business process modeling language selection and/or evaluation

\begin{tabular}{|c|c|c|c|c|}
\hline No & $\begin{array}{l}\text { Modeling language evaluation } \\
\text { or/and selection solution }\end{array}$ & $\begin{array}{l}\text { Goal is } \\
\text { considered }\end{array}$ & $\begin{array}{c}\text { Goal is } \\
\text { formalized }\end{array}$ & Description \\
\hline 1. & $\begin{array}{l}\text { Use of certain modeling } \\
\text { languages for certain modeling } \\
\text { goals [4], [8], [9], [15] }\end{array}$ & + & - & $\begin{array}{l}\text { Particular modeling languages } \\
\text { for certain tasks of the } \\
\text { business process management } \\
\text { lifecycle }\end{array}$ \\
\hline 2. & $\begin{array}{l}\text { Selection of the modeling } \\
\text { language using BWW ontology } \\
\text { [27] }\end{array}$ & + & + & $\begin{array}{l}\text { Intersection of the modeling } \\
\text { goal and the modeling } \\
\text { languages }\end{array}$ \\
\hline 3. & $\begin{array}{l}\text { Estimation of the modeling } \\
\text { language characteristics [10], } \\
\text { [11], [12], [13], [14] }\end{array}$ & - & - & $\begin{array}{l}\text { Qualitative or quantitative } \\
\text { characteristics of the modeling } \\
\text { languages }\end{array}$ \\
\hline 4. & $\begin{array}{l}\text { Adaptation, configuration or } \\
\text { scaling the content of the } \\
\text { business process model [16], } \\
{[17],[18],[19]}\end{array}$ & - & - & $\begin{array}{l}\text { Particular modeling language } \\
\text { for different purposes }\end{array}$ \\
\hline 5. & $\begin{array}{l}\text { Transformations between } \\
\text { different abstraction levels or } \\
\text { perspectives [20], [21], [22], [23], } \\
\text { [24], [25] }\end{array}$ & $+/-$ & - & $\begin{array}{l}\text { Particular modeling language } \\
\text { for a certain abstraction level or } \\
\text { perspective }\end{array}$ \\
\hline
\end{tabular}

According to Table 1, it can be concluded that most of the solutions do not provide the formalization of the modeling goal sufficiently. Either the modeler should decide which modeling language is more suitable for a particular goal, or use of the offered modeling language without justification and estimation of the alternatives.

\section{Grouping of Business Process Modeling Goals}

Business process models are an essential issue in enterprise operations and management because business process modeling is the central activity for solving a wide range of tasks, such as documentation, communication, business improvement, and capturing requirements for software design. Moreover, business process modeling application areas are still rapidly expanding. Thus there is a rising number of possible business process modeling goals. In this paper we propose the grouping of the business process modeling goals that is based on the analysis of more than 60 information sources. The proposed grouping of the business process modeling goals is shown in Figure 2 and described in the remainder of this section. In this grouping, the business process modeling goals are divided into five main groups: (A) business process graphical reflection, (B) visual analysis of different business process aspects, (C) business process analysis with quantitative methods, (D) design of the business process for further automation and (E) creation of the business process model for further implementation (develop executable business process model). The details for each group are given in the corresponding subparagraph in Figure 2. The above mentioned groups of modeling goals differ with respect to the content of a target business process model, type of representation, and degree of details. This list of the business process modeling goals is not final and can be to expanded.

\section{A. Business process graphical reflection}

This group includes modeling goals that require the creation of the visual reflection of the business process at the high level of abstraction. The created diagram should be comparatively simple and easily understandable, ignoring unnecessary implementation details and without strict requirements regarding the syntax correctness. The goals of this group may include such verbs as "to document", "to use for communication", "to use for training", "to make an overview", 
"to use for management", etc.; for instance:

- Identify and document the business process (e.g., [2]) - the first step in the business process management is its discovering and documentation. For this purpose the graphical models are developed, that describe how performers, involved in this business process, use inputs to perform appropriate outputs, what tools they use, and how they make decisions. The discovery and documentation of the business processes improve the transparency of the enterprise performance, increase the awareness of the business process structure, provide the repeatability of the business processes performance and accumulate the experience about the business process performance. As the knowledge about the business process performance can be only partial, it is necessary to provide the opportunity to create the sketch of the business process. It means that the modeling language should not have strict requirements with respect to the model syntax correctness.

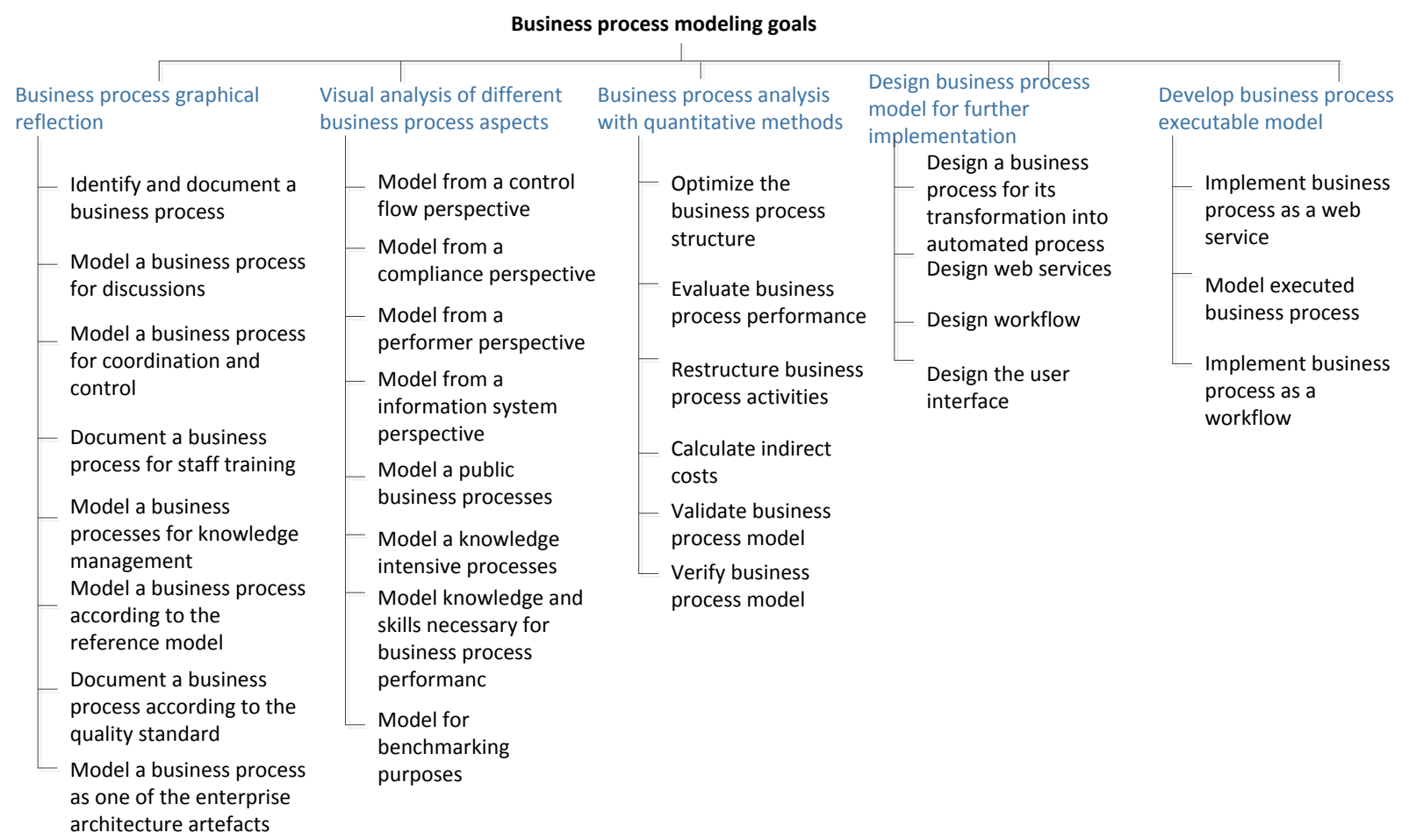

Figure 2. Groups of business process modeling goals

- Model a business process for discussions (e.g., [3]) - during business process modeling, it is often necessary to ensure co-operation between representatives of different problem domains: business analysts, domain experts, external consultants, managers, enterprise employees, IT experts, etc. Business process models allow for unifying the heterogeneous knowledge of the individuals involved concerning the existing or designed business processes. Taking into account that not all individuals involved in the discussions are experts in the business processes modeling, it is important to choose an intuitively understandable modeling language, thus providing the necessary expressiveness of the models and facilitating communication between the individuals.

- Model a business process for coordination and control (e.g., [5]) - for different management levels it is necessary to provide business process models with different degree of details regarding everyday coordination and control. For instance, top level managers are responsible for the performance of an enterprise as a whole, thus they need a holistic overview of key business processes. Models should be sufficiently abstract in order to compensate for complexity caused by a large number of business processes. On 
the other hand, operational managers and process owners are responsible for particular business processes, thus they need more detailed models that describe the internal structure of the business processes.

- Document a business process for staff training (e.g., [29]) - business process models can be used for enterprise personnel training, so that each employee could determine his/her input into the total productivity of the enterprise, as well as to inform personnel about the changes in the business processes, to unify understanding between the enterprise employees of business processes performed, or to train new employees.

- Model a business process for knowledge management (e.g., [10]) - knowledge about the business processes performance is the enterprise intellectual capital. Thus, business process modeling is a way to externalize the intangible employees' knowledge of the business process execution. Business process models created can be saved in the enterprise repositories and used for the creation of new knowledge or for sharing and/or distributing the existing knowledge.

- Model a business process according to the reference model (e.g. [30]) - business processes typical for a certain problem domain can be described using appropriate reference models, e.g., SCOR (Supply-Chain Operations Reference), DCOR (DesignChain Operations Reference), CCOR (Customer-Chain Operations Reference) ${ }^{1}$, APQC (APQC's Process Classification Framework) ${ }^{2}$, VRM (Value Reference Mode) ${ }^{3}$, SAP BPR (SAP Business Process Repository), etc.

- Document a business process according to the quality standard (e.g., [12]) - according to particular international standards (e.g., ISO 9000) the enterprises have to describe their business processes.

- Model a business process as one of the enterprise architecture artefacts (e.g., [12]) here the goal is to create a business process model as one of the enterprise architecture views.

\section{B. Visual analysis of different business process aspects}

This group of modeling goals requires the creation of the graphical representation of a business process in order to analyze it and obtain necessary conclusions. For comprehensive business process analysis, the modeler has to create different views of the business process, emphasizing the business process properties relevant for a given modeling goal. Unlike the previous group of business process modeling goals, a business process model here is created at the lower level of abstraction. Thus, graphical models can be used not only for business process documentation and overview, but also for their analysis and reengineering. Consequently, the business process models are analysed by qualitative methods or business process improvements are carried out by a trial and error method. The descriptions of the goals of this group may include such verbs as "to model from ... perspective", "to model in order to analyse ...", "to model in order to improve ..."; for instance:

- Model from a control flow perspective (e.g., [31]) - refers to detailed representation of business process execution structure, indicating the parallel and sequential activities, alternative execution paths, and exception and fault handling scenarios.

- Model from a compliance perspective (e.g., [32]) - in modeling the business process, the correspondence to internal business rules (long-term agreements, internal regulations, business protocols, operational procedures, quality standards, etc.), and external regulations (legislation, industrial standards, international quality standards, etc.) is provided. Business rules and regulations influence the procedures for the business process activities, incoming and outgoing data, pre-conditions and post-conditions, events and role

\footnotetext{
http://www.apics.org/

${ }^{2} \mathrm{https}: / /$ www.apqc.org/pcf

${ }^{3}$ http://www.value-chain.org/
} 
assignments of business processes. In case the changes are introduced into business rules and regulations, the appropriate business processes should be timely modified.

- Model from a performer perspective (e.g., [33]) - with the business process description, it is possible to define the required personnel and resources for process execution and create corresponding job descriptions.

- Model from an information system perspective (e.g., [34]) - here the goal is to define the possibilities of the business process automation when creating new computer systems or modifying the existing ones. Modeling languages, which are traditionally used for the development of information systems, are more suitable for solution domain analysis than for problem domain analysis. Business process modeling enables the development of information systems based on business research. Using business process models it is possible to obtain well defined business requirements and transform them into semantically rich descriptions that can be used further for creation of different types of software artefacts.

- Model public business processes (e.g., [4]) - refers to providing an inter-organizational cooperation between the enterprises. Here it is necessary to document so called public processes that are visible for external clients or partners. For this purpose it is necessary to hide the details of the private business processes, which should not be visible externally. This can be done by eliminating or hiding particular details of private business process models.

- Model knowledge intensive processes (e.g., [35]) - in knowledge intensive organizations, for business process change management, it is essential to identify the knowledge which is necessary for performing the business processes and knowledge which emerges as the result of the business process execution.

- Model knowledge and skills necessary for business process performance (e.g., [35]) here business process models are used in order to identify, plan, and manage knowledge which is necessary for performing business process activities. The models can be also used for identifying the owners of process data, information, and knowledge; for identifying, planning, and managing knowledge required for participating in a particular activity and linking this knowledge to the organizational competence model and roles; for improving the understanding of knowledge usefulness, validity, and relevance for particular activities; and for enabling competence requirements management and proactive training based on a process reengineering impact analysis.

- Model for benchmarking purposes (e.g., [30]) - here the goal is to create the description of the enterprise business processes in order to make a comparison with business processes of other enterprises that have a similar scope of activities. Based on the comparison results, the enterprise can make decisions concerning long-term improvements more effectively and efficiently.

\section{Business process analysis with quantitative methods}

The modeling goals of this group also intend to use business process models for analysis purposes. However, the difference from the previous group is that the analysis is based not only on the visual representation of the business process, but also on the quantitative indicators. Therefore business processes models should be described with formal graphical languages or with mathematical and algorithmic languages which may not have graphical representations. As a result, the business process simulation, restructuring, and optimization in a computerized environment are possible. For instance, as a result of business process model quantitative analysis, it is possible to calculate the expenses and idle time for technical facilities and human resources, to identify value added processes, to identify the possibilities to optimize the performed activities, etc. The descriptions of the goals of this group may include such verbs as 
"to evaluate", "to restructure", "to improve" "to optimize", "to validate", "to verify"; for instance:

- Optimize the business process structure (e.g., [36]) - the business process model is analysed in order to define deadlocks, synchronization possibilities, and cycles, to exclude trivial activities, to change the granularity level of the process, and other similar purposes. This type of analysis is possible in cases where the business process is described with formal mathematical methods.

- Evaluate business process performance (e.g., [12]) - here business process models are used in order to evaluate the efficiency of the business using quantitative parameters (for instance, KPIs), by simulating the performance of this business process with the help of dedicated computer programs. The results obtained can be used for evaluation of business processes before their introduction into a real life environment. For instance, the following issues can be evaluated:

- business process results - how much and what has been developed/produced/serviced as a result of business process performance,

- business process expenses - what resources it is necessary to spend in order to reach the necessary results and what will be the expenses,

- business process structure - which is the critical path, where are bottle necks, where are the queues or deadlocks formed, what are the value added activities, what are the automation possibilities,

- business process productivity - what is the relationship between the results and time spent to achieve them,

- business process efficiency - what is the relationship between the results and resources spent.

- Restructure business process activities (e.g., [37]) - the goal is to define the sequence of the business process activities that would minimize performance time, allow sharing resources more efficiently, and decrease the expenses. This type of analysis is based on algorithmic and analytical models and methods such as of genetic programming, industrial process planning, scatter storage, etc.

- Calculate indirect costs (e.g., [33]) - here business process models are enriched with parameters which are necessary for calculating indirect costs.

- Validate business process model (e.g., [4]) - here the aim is to check if the business process performance in a particular context corresponds to the initial requirements. The validation can be performed via process iteration simulation.

- Verify business process model (e.g., [4]) - here the aim is to check the correctness of the business process model independent of the context, for instance, by defining idle time, deadlocks, or conditions that are impossible to fulfil.

\section{Design the business process model for further implementation}

The modeling goals of this group are used for the business process automation design, when the business process performance and/or management can be partially or fully overtaken by computer systems. Usually a graphical model is created. However, the difference from the previous groups of modeling goals is that the modeling is performed for the machines, not for the people. When the business process model is made for the people, it is not necessary to include all business process details, because many things are self-explanatory or can be easily derived from the context. However, when business processes are modeled in order to be automated, it is necessary to define all the details regarding their performance. The models created describe the functioning of the computer system independent of the chosen implementation environment. Thus the business processes should be modeled, not only with sufficient amount of detail, but additionally their descriptions should be verified according to language syntax requirements. The 
descriptions of goals of this group can include such verbs as "to design", "to automate", etc: for instance:

- Design a business process for its transformation into an automated process (e.g., [38]) - the goal of modeling is to create a business process model the performance of which is automated with the help of software. A business process model is created with sufficient level of details and is complemented with parameters so that it can be transformed into the performance language, e.g., corresponding to model-driven architecture (Model-Driven Architecture, $M D A$ ) approach.

- Design web services (e.g., [39]) - the business process model is created in order to design loosely coupled systems by using web service technology. There are two types of implementation solutions: business process orchestration and business process choreography. Orchestration foresees the specifying of the business process performance structure by defining the internal and external web-services, while choreography supports exchange of messages between the participants but the internal structure of the business process does not have a direct definition.

- Design workflow (e.g., [39]) - before creating the workflow specification, it is necessary to understand the corresponding business process via creating the business process model. By changing the abstraction level of the business process model, a description of the workflow is obtained which is suitable for processing by the workflow management system.

- Design the user interface (e.g., [40]) - the design of the user interface is based on business process models. It is possible to perform automated interface design, by transforming the business process into software code.

\section{E. Develop executable business process model}

This group includes the modeling goals of specifying business processes in terms of implementation elements available in a given platform. Thus, the goal is to develop the solutions for particular business process technical implementations. As the models created are sufficiently detailed, the transformation into implementation artefacts is possible (e.g., into database objects or executable descriptions). For this purpose the models are created using the executable modeling languages, such as $\mathrm{BPEL}^{4}$ or programming languages. The descriptions of the goals of this group can include such verbs as "to implement", "to design", "to model for execution", etc.: for instance:

- Implement business process as a web service (e.g., [40]) - if the business process is performed as a set of interacting web services, the business process model could describe the web service structure in machine readable format. Each business process model can be regarded as an individual web service or specify the interaction of a set of different web services.

- Model executed business process (e.g., [41]) - during the business process implementation is possible to enrich the conceptual process model with implementation details and transform it into an executable model which can be run on the appropriate platform. Usually this solution corresponds to a process oriented information system approach (e.g., web services, business process management or workflow management information systems).

- Implement business process as a workflow (e.g., [42]) - workflow specification is developed on the basis of the business process description, which includes all the details necessary for the workflow implementation.

\footnotetext{
${ }^{4}$ http://www.bpmn.org/
} 


\section{Business Process Abstraction Types}

A natural way to learn about the world around us is its modeling. When we create models, the subject under research is replaced by another mental or physical object, which is more convenient, safer, or cheaper to use than the original. According to such general explanation of the model any kind of modeling requires the creation of the abstraction of the research object. In a general sense, abstraction is understood as highlighting the important properties of the research object or phenomenon and ignoring unimportant properties or creating the general concepts or ideas from the set of objects or facts [43]. Abstraction facilitates understanding of complicated things, replacing the real object with a simplified and generalized representation, e.g., the model of that object. There are a number of abstraction techniques, but by analyzing the business process modeling language specifications (BPMN, DFD, IDEF0, EPC, UML AD, etc.), and business process modeling framework documentation [44], [45], [46], [47], [48], it is possible to identify three most commonly used business process abstraction types:

- Filtration of the business process elements according to a certain modeling perspective.

- Generalization from the details about the business process execution according to the selected level of uncertainty.

- Reducing the complexity by "hiding" part of the business process in the lower level of the decomposition.

Each of these types of business process abstraction is discussed in more detail in Subsections 4.1-4.3.

\subsection{Perspective}

Real business process has an almost infinite set of different elements. Creating business process abstraction, a final set of elements is selected, eliminating other ones. The unnecessary elements are filtered according to the defined criteria. In the case of business process modeling, these criteria are often replaced by the concept of perspective that is the viewpoint from which the observer explores certain part of the research object without seeing others parts [49]. A business process model that is created from certain perspective is called a view [50], [26].

In some cases in the literature the perspective concept is replaced by other similar terms, such as the viewpoint or the aspect. An aspect is a certain part of the subject that is visible from a certain position [26]. A viewpoint is a position from which an observer sees only a certain part of the object or estimates the phenomena of the surrounding world [43]. These concepts are semantically similar and interchangeable.

When modeling the same business process from different perspectives, the business process is studied in the "width". In other words, a derived number of several models creates a comprehensive impression of the business process, by this way exploring the different parts of the business process (Figure 3).

\subsection{Generalization}

Another business process abstraction technique is a generalization. Depending on the purpose of the modeling, the same business process can be modeled with differing precision. The degree of uncertainty of the business process modeling is selected according to the level of generalization. In the lowest generalization levels the business process model includes the most details about the business process execution, thus minimizing the uncertainty and inaccuracy. In the highest generalization levels the model is created with coarser granularity and is less specific in content. This may be achieved, for example, by increasing the degree of uncertainty, abstracting from implementation details, dissembling the obvious things, ignoring the insignificant differences, and generalizing similar behavior. Using the generalization technique it is possible to create a 
multi-layer model of the business process. Between the lowest and the highest generalization levels there is a link "is the concretization", that is, lower level models are more accurate representations of the higher level models. Models of the same business process at different generalization levels are schematically presented in Figure 4. For instance, the same business process may be modeled initially at the conceptual level and then at the analysis or execution level.

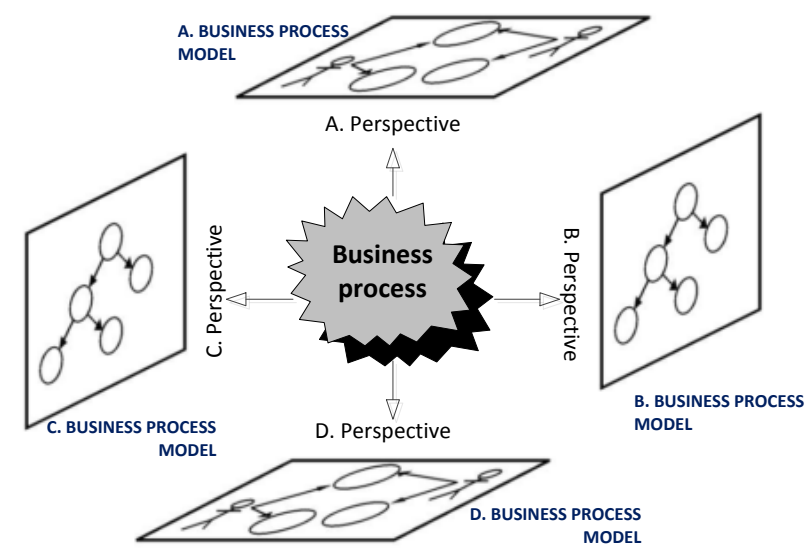

Figure 3. Business process modeling from different perspectives

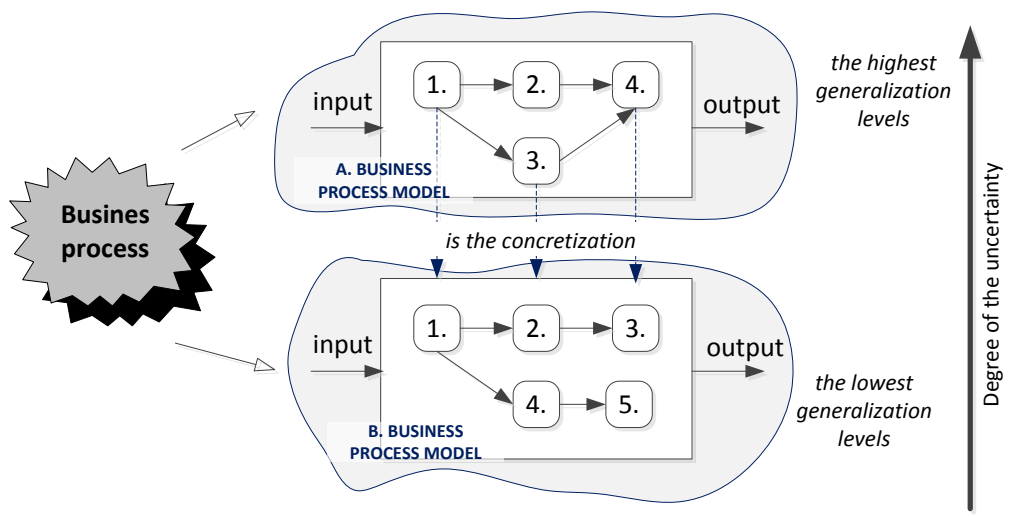

Figure 4. Business process modeling at different generalization levels

\subsection{Decomposition}

One more way to hide unnecessary details is decomposing the business process into the subprocesses. Every sub-process is a set of the business process activities that is "hidden" at the level of lower level of detail, thus simplifying the understanding of the complex business process. The concept of decomposition sometimes is replaced by the concept of granularity, which is the degree to which the process is broken down into smaller components [50]. The coarse-grained business process consists of a smaller number of the components that are larger in size. In contrast, the fine-grained business process is divided into a larger number of components that are smaller in size.

In the case of generalization each level of abstraction is created as an individual model, but in the case of decomposition, usually one model that is divided into different decomposition levels is created. Between the models in the upper and lower decomposition levels there is a relationship "is a composition" or "consists of". Modeling of one and the same business process at different decomposition levels is schematically presented in Figure 5. 


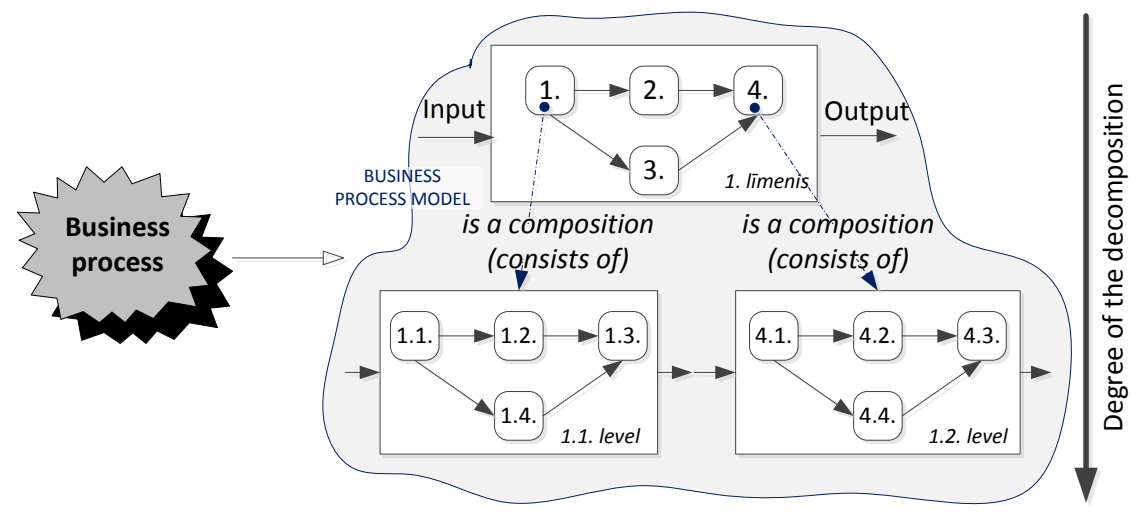

Figure 5. Business process modeling at the different decomposition levels

\section{Formalization of the Business Process Modeling Goal}

By analyzing several business process modeling language specifications (BPMN, DFD, IDEF0, EPC, UML AD, etc.) and business process modeling framework documentations [45], [46], [47], [28], [49], we have found that, in order to create the business process model for a particular goal, all three types of abstraction mentioned in Sections 4.1-4.3 should be used. Consequently, any business process modeling goal may be formally described by three parameters: perspective from what viewpoint the abstraction should be designed, generalization level - with what degree of uncertainty the business process should be explored and decomposition level - the necessary granularity of the business process model. According to that argument, the business process modeling goal can be defined as follows:

"The Business process modeling goal represents intention to create the business process abstraction from a certain perspective, at the appropriate generalization and decomposition levels. The Business process modeling goal can be formalized by the expression $G_{B P}=\{G L, D L$, $P\}$, where $G_{B P}$ is the business process modeling goal, $G L$ is the parameter representing the generalization level, $D L$ is the parameter representing the decomposition level, and $P$ is the parameter representing the modeling perspective."

Each parameter in the $G_{B P}$ expression can have a certain "scale" of "values". Figure 6 illustrates interdependence of parameters for the business process model created for the goal $G_{B P}$ $(P j, G L i, D L k)$ that has been created at the generalization level $i$, from the perspective $j$ at the decomposition level $k$.

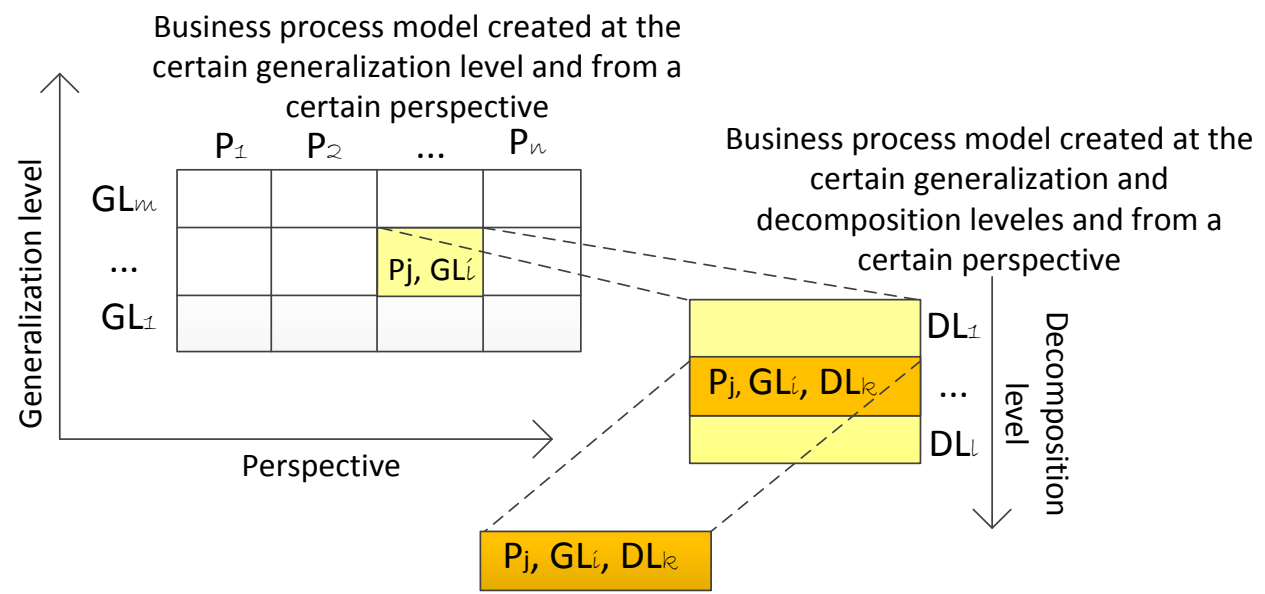

Figure 6. Interdependence between business process modeling goal's parameters 
As can be seen from Figure 6, there are the following relationships between the business process modeling goal's parameters:

- Decomposition level is determined by specifying the necessary generalization level. In other words, for each generalization level there is an appropriate hierarchy of the decomposition levels. So first it is necessary to determine the desired degree of uncertainty of the business process model, and then it is possible to decompose the business process model into appropriate decomposition levels.

- Decomposition levels are not mandatory, that is, if the business process model contains relatively few elements, then the decomposition into the lower levels is not required. Otherwise, the definition of the level of generalization is mandatory.

- Perspectives are determined independently of the generalization and decomposition levels. This means that values of the perspective axis are possible to be specified regardless of generalization and decomposition levels axis values.

- Generalization and decomposition allow obtaining vertical abstractions (to explore in depth) and perspectives allow creating horizontal abstractions (to explore the width).

Taking into consideration the business process modeling goal definition proposed in this section, the following general requirements for the choice of the appropriate business process modeling languages could be defined:

- To determine the modeling language suitability to the specific perspective, it is necessary to check whether the modeling language offers the necessary syntactical constructs to describe the desired business process parameters. The coverage must be maximally full; otherwise it will be necessary to combine several modeling languages. In this situation, it is desirable to choose those modeling languages that minimally duplicate each another.

- To determine the modeling language suitability for the generalization level, it is necessary to assess with what degree of uncertainty the modeling language allows the business process to be described. Creating a business process at the highest levels of generalization, the focus is on the understanding of reality, and it is not desirable to spend time to understand how to use the modeling language. In other words, the use of the modeling language must be natural and independent from the future implementation of the business process model. In addition, at the higher levels of generalization it is often not possible (and often not necessary) to obtain detailed knowledge about the business processes performance. Thus, a modeling language that does not complicate the simple things should be chosen. If the business process model is built for human comprehension, there is no need to reflect all details about the business process, as a number of things might be self-evident. However, for the use by computer systems, the business process models must be formal, and detailed.

- To determine the modeling language suitability to the decomposition level, it is necessary to indicate whether the business process modeling language provides appropriate syntactical constructs.

A particular modeling language can be useful for several generalization levels and perspectives. As well as that, modeling language could have various subsets of the syntactical constructs or have different extensions that are appropriate to different modeling goals.

For characterizing the business process modeling goal parameters we use the Business Process Modeling Framework illustrated in Figure 7. The framework has three dimensions that are defined according to the modeling goal's parameters. Generalization and decomposition levels are the vertical dimensions, and perspective - the horizontal dimension. Each framework dimension has appropriate "scale" of "values" shown with the abbreviation $G L_{i}$ - for generalization, $D L_{i}$ - for decomposition, and $P_{i}$ - for perspectives. By modeling the business process at the certain generalization and decomposition levels and from a certain perspective, the business process model that meets the requirements of a certain modeling goal can be obtained. 
The "scale" of the generalization is based on the classification of the business process modeling goals that are proposed in this paper. Thus, the following generalization levels are included in the framework (Figure 7):

- GL1. Overview level - is appropriate when the holistic graphical view of the company's key business processes should be created, including collaborative business processes with external partners and/or customers. Usually the information of all key business processes is reflected in one model thereby a high level of abstraction is required in order to compensate for the complexity caused by a large number of elements. The overview level may be useful for managers and business analysts.

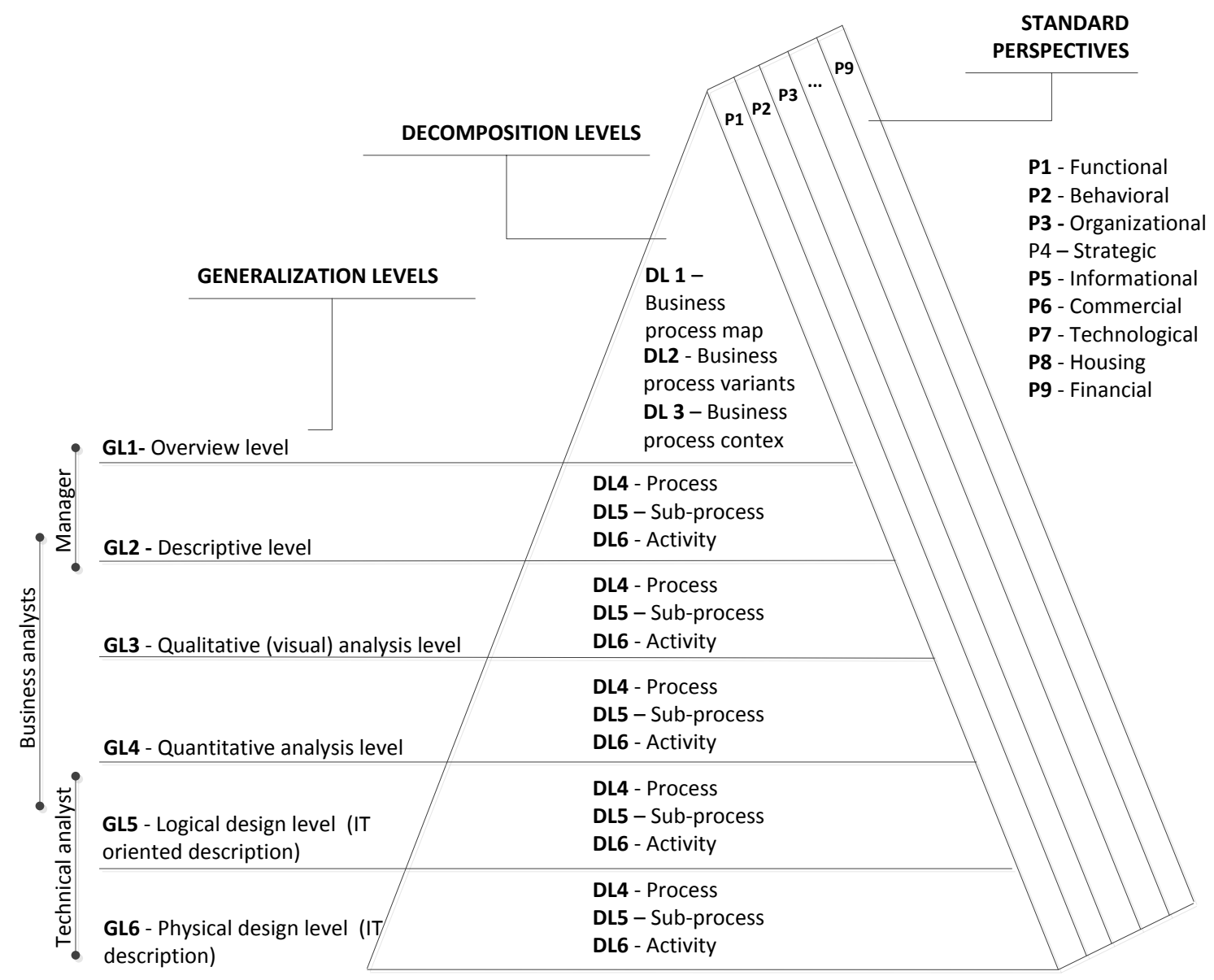

Figure 7. Business Process Modeling Framework

- GL2. Descriptive level is appropriate when, in contrast to the previous level, instead of modeling all key business processes, a certain business process should be modeled. The graphical representation of the business process should be created at the level of precision appropriate for business process documentation, communication with customers, staff training, etc. Graphical representations created must be relatively simple, intuitively understandable, avoiding self-evident things, ignoring unnecessary implementation details, and without strong syntactic rules. The models created may be useful for different levels of managers, process owners, business analysts, customers, partners, and other employees.

- GL3. Qualitative (visual) analysis level is appropriate to visually analyze the various business process aspects. At this level the business process maturity is gradually increased. The business process model is enriched with details that are required for analysis of the business process characteristics from different perspectives in order to identify process improvement opportunities, to specify the requirements for the support systems, to identify outsourcing opportunities, to identify possible business services, etc. Thus, it is necessary to 
develop the "rich" and sufficiently precise model that could be used for obtaining a useful conclusion about business process improvement opportunities. At the same time the models created must be sufficiently intuitive. Models developed at this level may be useful for business analysts.

- GL4. Quantitative analysis level is to analyze the business process by quantitative methods. So, in contrast to the previous level, the analysis is based on numerical indicators rather than on the visual evaluation of the graphical representation. The models created are designed for restructuring, improving, and optimizing the business process according to the quantitative results of the analysis, e.g., to reduce costs, to provide a more efficient allocation of resources, to improve customer service, to identify the value added processes, to optimize the structure of the process etc. The business process should be modeled in detail by creating formal parameterized models that can be used for analysis with mathematical or analytical methods. Models created at this level also may be useful for business analysts.

- GL5. Logical design level is appropriate for modeling goals that intend to design the business process automation. The logical design level focuses on the business process support with IT. In other words, it is important to precisely model those business process parts that will be supported by the process aware information systems [51], such as workflow management systems, business process management systems, e-commerce systems etc. As a result the developed graphical representations could be transformed into executable language. Thus this level is appropriate only for business processes that are modeled in sufficient detail and their descriptions are verified and validated according to certain quality criteria. The models created may be useful for technical analysts and designers.

- GL6. Physical design level is appropriate to create the executable business process descriptions that could be transformed into IT artefacts (such as database objects or program code). At this level business process description has the largest number of details and the highest degree of accuracy and formalization. That is because the business process model is enriched with details that are necessary for the model's transformation into the program code. Thus, additional validation restrictions are required at this level. Models created may be useful for technical analysts and designers.

Summarizing multiple sources that offer hierarchical decomposition structures of business processes, the hierarchical structure of business process decomposition is obtained, and this is shown in Table 2.

Table 2. The business process decomposition levels

\begin{tabular}{|c|c|c|c|c|c|c|c|c|c|}
\hline \multicolumn{2}{|c|}{ Decomposition level } & กิ & ק్ & 仺 & 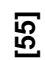 & 움 & 导 & $\underline{\mathbf{\Phi}}$ & $\sqrt{6}$ \\
\hline \multirow{3}{*}{ 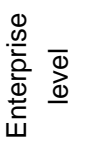 } & Process map & + & + & + & \pm & - & + & + & + \\
\hline & Process variants & + & + & + & + & 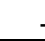 & - & - & - \\
\hline & Process context & - & - & - & - & + & - & + & - \\
\hline \multirow{3}{*}{ 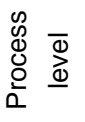 } & Process & + & + & + & + & - & + & + & - \\
\hline & Sub-process & - & + & + & \pm & - & - & - & - \\
\hline & Activity & - & - & + & + & - & - & - & - \\
\hline
\end{tabular}

The decomposition levels reflected in Table 2 are used for defining the decomposition "scale" in the Business Process Modeling Framework:

- DL1. Business process map - includes the enterprise's top-level business processes such as customer service management, supply chain, human resource management, accounting, etc. At this level the business process internal structure is not modeled, thus representing processes as "black boxes". This level is closely associated with the company's strategies 
and operational goals. It is possible to describe not only the execution sequence of the top-level business processes, but also to show other links, such as decomposition, calling, realization, specialization.

- DL2. Business process variant level - represents the division of the top-level business processes into elementary business processes that belong to the same group or reflect the various variants of the same top-level business process. Elementary processes belong to the same group if they realize the same modeling goal but differ in the manner in which this goal is achieved. Additionally, the elementary business process can represent the different alternative versions of the top-level business process, for instance, the several variants of the TO-BE models. Also, at this level, the business process internal structure is not modeled.

- DL3. Business process contextual level - describes a certain business process execution context, defining business process customers, the basic values that are created, resources that are used, main partners, and other elements.

- DL4. Business process level - the first level that represents the business process internal structure (the business process is modeled as a "white box"), with clearly defined process borders, describing the possible execution paths, decision points, resources used, and other elements.

- DL5. Sub-process level - at this level detailed modeling of certain fragments of the business process is performed. In other words, the business process is divided into activities at the lower levels of decomposition, thus reducing the complexity of the business process model.

- DL6. Activity level - at this level a certain process activity is expanded, reflecting all the necessary information for carrying out the activity, e.g., information about performers, time constraints, resources, conditions, restrictions and other elements.

Regarding perspectives, it is possible to distinguish between standard perspectives and user perspectives. User perspectives can include any set of business process elements depending on the domain of interest. They are defined by modelers, specifying what business process elements belong to a particular perspective. These perspectives are not discussed below, but can be added to the perspective "scale" if necessary. Standard perspectives are formed by a pre-defined set of business process elements. The following standard perspectives are proposed in the related work [58], [59]:

- P1. Functional perspective - to represent, which process elements are being performed, and what flows of informational entities (e.g., data, artefacts, products) are relevant to these process elements.

- P2. Behavioural perspective - to represent when process elements are performed (e.g., sequencing), as well as aspects of how they are performed through feedback, loops, iteration, complex decision-making conditions, entry, and exit criteria.

- P3. Organizational perspective - to represent where and by whom in the organization the elements of a process are performed, the physical communication mechanisms used for transfer of entities, and the physical media and locations used for storing the entities.

- P4. Informational perspective - to represent the informational entities produced or manipulated by a process; these entities include data, knowledge, artefacts, products (intermediate and end ones), and objects; this perspective includes both the structure of informational entities and the relationships among them.

- P5. Strategic perspective - to coordinate and integrate the activities of various functional areas of a business in order to achieve long-term organizational objectives.

- P6. Commercial perspective - to represent how a business process interacts with an external environment or, in other words, which relationships exist between an organization and its customers and suppliers. 
- P7. Technological perspective - to represent the quality means supporting the execution of tasks, the extent to which technical means offer appropriate support to the execution of tasks, and the ability to adapt the technological means to changing circumstances.

- P8. Housing perspective - to represent the location of departments and geographical distribution of customers and support of the office environment in the execution of tasks and business process.

- P9. Financial perspective - to represent the cost of process execution.

\section{Example of Using the Business Process Modeling Framework and Modeling Goal Parameters}

To illustrate how the Business Process Modeling Framework could be used for the definition of the modeling goal parameters, the bank business process "Crediting the legal persons" is considered. It is modeled according to the following four goals:

- G1 - Initially, according to the new strategic objectives, the bank has decided to concentrate on the crediting of the legal persons. The business process "Crediting the legal persons" is becoming the main value added production line. As a result the business process is reorganized so as to ensure maximum support for legal persons.

- G2 - In the second case, the bank has decided to document the restructured business process "Crediting the legal persons" in order to develop procedure descriptions for employees. These descriptions will be used to train the responsible employees according to new procedures.

- G3 - In the third case, the model of the business process "Crediting the legal persons" is used to define required knowledge, skills, and responsibilities that are necessary to carry out each activity in the process.

- G4 - Finally the bank has decided to develop a web service for the improved business process "Crediting the legal persons". For this purpose, initially, the detailed description of the business process should be developed using appropriate modeling language, and then it should be transformed into an executable model.

The first modeling goal is related to the strategic analysis, the second - to the business process documentation, the third - to the personnel training, and the fourth - to the development of the application. These various business process modeling cases (M1-M5) are illustrated in Figure 8.

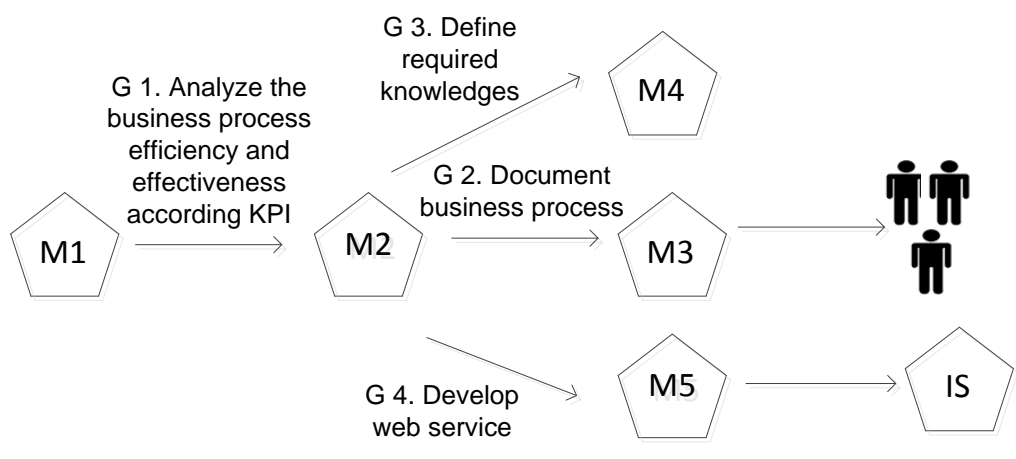

Figure 8. The modeling of the business process "Crediting the legal persons" according to different modeling goals

As Figure 8 shows, each of the modeling goals requires creating different business process abstractions. Table 3 summarizes the requirements for the business process parameters for the above listed modeling goals. 
In Table 3 for the first modeling goal, it is necessary to develop a sufficiently detailed and formal business process model that can be used for analysis and simulation. For the second modeling goal it is necessary to build a sufficiently simple and general model at the high level of abstraction. The third modeling goal requires the developing of a model that could be used for visual analysis. And finally, according to the fourth modeling goal, the model should be created for the "machines" rather than for the people. Thus the model should be developed as the detailed, unambiguous, verified, and machine-readable representation of the business process.

Table 3. The values of parameters of the modeling goals according to the Business Process Modeling Framework

\begin{tabular}{|l|l|l|l|l|}
\hline No. & Modeling goal & Perspective & Generalization level & Decomposition level \\
\hline 1. & $\begin{array}{l}\text { Analyze the } \\
\text { business process } \\
\text { efficiency and } \\
\text { effectiveness } \\
\text { according to key } \\
\text { performance } \\
\text { indicators (KPI) }\end{array}$ & $\begin{array}{l}\text { Behavioural } \\
\text { perspective, } \\
\text { organizational } \\
\text { perspective, } \\
\text { strategic perspective, } \\
\text { commercial } \\
\text { perspective }\end{array}$ & $\begin{array}{l}\text { Quantitative } \\
\text { analysis level }\end{array}$ & Business process level \\
\hline 2. & $\begin{array}{l}\text { Document business } \\
\text { process }\end{array}$ & Behavioral perspective & Descriptive level & Business process level \\
\hline 3. & $\begin{array}{l}\text { Define required } \\
\text { knowledge }\end{array}$ & $\begin{array}{l}\text { Informational } \\
\text { perspective }\end{array}$ & $\begin{array}{l}\text { Qualitative (visual) } \\
\text { analysis level }\end{array}$ & Business process level \\
\hline 4. & Develop web service & Technical perspective & Logical design level & Business process level \\
\hline
\end{tabular}

Creating business process models at the descriptive level, attention should be focused on the understanding of the reality, and it is not desirable to spend time to understand how to use the modeling language. Thus, the modeling language should be intuitively understandable and easy to use. In contrast, when creating business process models at the logical and physical design levels, there is no need to spend time in creating readable and easily understandable models for business executives. Thus, the modeling language should be formal and machine executable.

It is possible to define a minimal set of business process modeling language elements for each value of business process modeling goal parameters (discussion of this issue is beyond the scope of this paper). When the set of language elements is known, the language that is closest to this set of elements can be chosen.

\section{Conclusion}

On the basis of analysis of business process modeling language specifications and business process modeling framework documentations it has been identified that the abstractions (models) of business processes are usually created using the following techniques: generalization, decomposition, and modeling from a particular perspective. This paper offers to use these abstraction types for the formalization of the business process modeling goal. For better usage of the modeling goal parameters the Business Process Modeling Framework is applied. Using this framework a modeler can choose the perspective and the levels of generalization and decomposition.

In the parallel researches, appropriate metrics and algorithms are developed for evaluating how modeling languages conform to the selected values of the modeling goal parameters [60]. For instance, in order to evaluate to what extent the business process modeling language conforms to the desired perspective, whether the modeling language offers syntactical constructions for all necessary business process elements should be measured. But, in order to evaluate conformity to the required generalization level, the flexibility and multiplicity of the 
modeling language should be evaluated. That is, for modeling at the highest generalization level, the modeling language should be the most flexible and provide, for each business process element, only one syntactical construction. It is different when modeling at the lower generalization levels.

The proposed solution uncovers complexity of business process modeling and is the first step towards development of a support system for evaluating conformity of business process modeling languages according to particular modeling goals, that could help to handle that complexity.

While the proposed goal formalization approach was helpful in cases verified so far, more experiments will be performed to evaluate whether it is possible to specify defined modeling goals according to the Business Process Modeling Framework in a larger number of cases.

The extended abstract of this paper is available in [61].

\section{References}

[1] W.M.P. van der Aalst, "A Decade of Business Process Management Conferences: Personal Reflections on a Developing Discipline," in Business Process Management, Springer-Verlag, Heidelberg, pp. 1-16, 2012. Available: http://dx.doi.org/10.1007/978-3-642-32885-5_1

[2] H.D.D. Garcia, "Evaluation of Data-Centric Process Modeling Approaches," Master thesis, Eindhoven, Eindhoven University of Technology, 2011.

[3] I. Bider, "Choosing Approach to Business Process Modeling." [Online]. Available: http://www.inconcept.com/JCM/january2005/index.html

[4] A. Lodhi, V. Koppen and G. Saake, "Business Process Modeling," in Active Research Areas and Challenges, Technical Report, 34 p., 2011.

[5] T.R. Browning, E. Fricke and H. Negele, "Key Concepts in Modeling Product Development Processes," Wiley InterScience, vol. 9, no. 2, pp. 104-128, $2006 . \quad$ Available: http://dx.doi.org/10.1002/sys.20047

[6] R.S. Aguilar-Saven, "Business Process Modelling: Reviewand Framework," in International Journal of Production Economics, vol. 90, no. 2, pp. 129-149, 2004.

[7] L. Aldin and S. de Cesare, "A Comparative Analysis of Business Process Modelling Techniques." [Online]. Available: http://aisel.aisnet.org/ukais2009/2/

[8] R. Burlton, "Perspectives on Process Modeling." [Online]. Available: http://www.bptrends.com/point-of-view-perspectives-on-process-modeling/

[9] A. Lonjon, "Business Process Modeling and Standardization." [Online]. Available: http://www.bptrends.com/publicationfiles/12-04\%20WP\%20BPM\%20and\%20Standardization\%20\%20Lonjon.pdf

[10] J. Recker, M. Rosemann, M. Indulska and P. Green, "Business Process Modeling: A Maturing Discipline?" [Online]. Available: http://bpmcenter.org/wp-content/uploads/reports/2006/ BPM-06-20.pdf

[11] P.F. Green, M. Rosemann and M. Indulska, "Ontological Evaluation of Enterprise Systems Interoperability Using ebXML," in EEE Transactions on Knowledge and Data Engineering, vol. 17, no. 5, pp. 713-725, 2005. Available: http://dx.doi.org/10.1109/tkde.2005.79

[12] P. Green and M. Rosemann, "Integrated Process Modeling: an Ontological Evaluation," in Information System, vol. 25, no. 2, pp.73-87, 2000. Available: http://dx.doi.org/10.1016/s0306-4379(00)00010-7

[13] M. zur Muehlen, J. Recker and M. Indulska, "Sometimes Less is More: Are Process Modeling Languages Overly Complex?" in EDOC Conference Workshop, pp. 197 - 204. IEEE Press, 2007. Available: http://dx.doi.org/10.1109/edocw.2007.30 
[14] F. Heidari, P. Loucopoulos, F. Brazier and J. Barjis, "A Meta-Meta-Model For Seven Business Process Modeling Languages," in Business Informatics (CBI), 2013 IEEE 15th Conference, IEEE Press, pp. 216-221, 2013. Available: http://dx.doi.org/10.1109/cbi.2013.38

[15]E.M. Nieto-Ariza, G. Rodríguez-Ortiz and J. OrtizHernández, "An Empirical Evaluation for Business Process Tools," in Advanced Software Engineering: Expanding the Frontiers of Software Technology, Springer, Heidelberg, pp. 77-84, 2006. Available: http://dx.doi.org/10.1007/978-0-387-34831-5_6

[16] R. Bobrik, M. Reichert and T. Bauer, "Parameterizable Views for Process Visualization." [Online]. Available: http://doc.utwente.nl/64125/

[17] A. Polyvyanyy, S. Smirnov and M. Weske, "Process Model Abstraction: A Slider Approach," in Enterprise Distributed Object Computing Conference, IEEE Press, pp. 325-331, 2008. Available: http://dx.doi.org/10.1109/edoc.2008.17

[18] S. Smirnov, H.A. Reijers, M. Weske and T. Nugteren, "Business Process Model Abstraction: A Definition, Catalog, and Survey," in Distributed and Parallel Databases, vol. 30, no. 1, pp. 63-99, 2012. Available: http://dx.doi.org/10.1007/s10619-011-7088-5

[19] M.L. Rosa, M. Dumas, A.H.M. ter Hofstede and J. Mendling, "Configurable Multi-Perspective Business Process Models," in Information Systems, vol. 36, no. 2, pp. 313-340, 2011. Available: http://dx.doi.org/10.1016/j.is.2010.07.001

[20] J. Dehnert and W.M.P. van der Aalst, "Bridging the Gap between Business Models and Workflow Specifications International," in Journal of Cooperative Information Systems, vol. 13, no. 3, pp. 5169, 2004. Available: http://dx.doi.org/10.1142/s0218843004000973

[21] J. Mendling and J. Ziemann, "Transformation of BPEL Processes to EPCs."

[22] A. Dreiling, M. Rosemann and W.M.P. van der Aalst, "From Conceptual Process Models to Running Workflows: A Holistic Approach for the Configuration of Enterprise Systems." Available: http://dx.doi.org/10.1016/j.dss.2007.02.007

[23] S. Brahe and B. Bordbar, "A Pattern-Based Approach to Business Process Modeling and Implementation in Web Services," in Service-Oriented Computing ICSOC 2006, Springer, Heidelberg, pp. 166-177, 2007. Available: http://dx.doi.org/10.1007/978-3-540-75492-3_15

[24] V. Hoyer, E. Bucherer and F. Schnabel, "Collaborative e-Business Process Modelling: Transforming Private EPC to Public BPMN Business Process Models," in Business Process Management Workshops, Springer, Heidelberg, pp. 185-196, 2008. Available: http://dx.doi.org/10.1007/978-3540-78238-4_20

[25] J. Mendling, K.B. Lassen and U. Zdun, "Transformation Strategies between Block-Oriented and Graph-Oriented Process Modelling Languages."

[26] MDA - The Architecture of Choice for a Changing World. [Online]. Available: http://www.omg.org/mda/

[27] W. Esswein, S. Stark and H. Schlieter, "The Selection of Modeling Grammars." [Online]. Available: http://subs.emis.de/LNI/Proceedings/Proceedings171/13.pdf

[28] P. Green and M. Rosemann, "Integrated Process Modeling: An Ontological Evaluation," in Information System, vol. 25, no. 2, pp. 73-87, 2000. Available: http://dx.doi.org/10.1016/s03064379(00)00010-7

[29] F. García, A. Vizcaíno and Ch. Ebert, "Process Management Tools," in IEEE Software, vol. 28, no. 2, pp. 15-18, 2011.

[30] P. Bolstorff and R.G. Rosenbaum, "Supply Chain Excellence: A Handbook for Dramatic Improvement Using the SCOR Model," USA, AMACOM Div American Mgmt Assn, 277 p., 2007.

[31] W.M.P. van der Aalst, A.H.M. ter Hofstede and A.P. Barros, "Workflow patterns," in Distributed and Parallel Databases, vol. 14, no. 1, pp. 5-51, 2003. Available: http://dx.doi.org/10.1007/978-0-387-39940-9_826 
[32] L. Businska, L. Penicina, M. Kirikova, I. Buksa, and P. Rudzajs, "Enterprise Modeling in the Eyes of the Accounting," in Proceedings of the 5th IFIP WG8.1 Working Conference on the Practice of Enterprise Modelling (PoEM 2012), Rostock, pp. 106-118, 2012.

[33] M. Reichert, S. Rinderle, and P. Dadam, "ADEPT Workflow Management System Flexible Support for Enterprise-Wide Business Processes Tool Presentation," in Business Process Management, Heidelberg, Springer, pp. 370-379, 2003. Available: https://doi.org/10.1007/3-540-44895-0_25

[34] J. Bicevskis, J. Cerina-Berzina, G. Karnitis, L. Lace, I. Medvedis, and S. Nesterovs, "Practitioners View on Domain Specific Business Process Modeling," in Proceedings of the 2011 conference on Databases and Information Systems VI: Selected Papers from the Ninth International Baltic Conference, Netherlands, IOS Press Amsterdam, pp. 169-182, 2011.

[35] L. Businska, M. Kirikova, "Knowledge Dimension in Business Process Modeling," in IS Olympics: Information Systems in a Diverse World (CAiSE Forum 2011), Heidelberg, Springer, pp. 186-201, 2012. Available: https://doi.org/10.1007/978-3-642-29749-6_13

[36] M. Fernandez-Ropero, R. Perez-Castillo, and M. Piattini, "Graph-Based Business Process Model Refactoring."

[37] A. Tiwari, K. Vergidis, and B. Majeed, "Evolutionary Multi-objective Optimization of Business Processes," in Soft Computing in Industrial Applications: Algorithms, Integration, and Success Stories, Heidelberg, Springer Berlin, pp. 293-301, 2010. Available: https://doi.org/10.1007/978-3-642-11282-9_31

[38] M. Indulska, J. Recker, M. Rosemann, and P. Green, "Process Modeling: Current Issues and Future Challenges," in Advanced Information Systems Engineering: 1st International Conference, CAiSE 2009, Heidelberg, $\quad$ Springer, pp. 501-514, $2009 . \quad$ Available: https://doi.org/10.1007/978-3-642-02144-2_39

[39] H. Mili1, G.B. Jaoude, E. Lefebvre, G. Tremblay, and A. Petrenko, "Business Process Modeling Languages: Sorting Through the Alphabet Soup," in ACM Computing Surveys (CSUR), vol. 43, no. 1, pp. 1-56, 2010. Available: https://doi.org/10.1145/1824795.1824799

[40] R. Dividino, V. Bicer, K. Voig, and J. Cardoso, "Integrating Business Process and User Interface Models using a Model-Driven Approach," in 24th International Symposium on Computer and Information Sciences, Guzelyurt, IEEE, pp. 492-497, 2009. Available: https://doi.org/10.1109/ISCIS.2009.5291872

[41] Y. Balouki, A. Balouki, M.E. Far, and A. Kriouile, "Transformation of Models in an MDA Approach for Collaborative Distributed Processes," in Collaborative Systems for Reindustrialization, Heidelberg, Springer, pp. 201-208, 2013. Available: https://doi.org/10.1007/978-3-642-40543-3_22

[42] J. Dehnert, W.M.P. van der Aalst, "Bridging the Gap between Business Models and Workflow Specifications International" in Journal of Cooperative Information Systems, vol. 13, no. 3, pp. 51-69, 2004. Available: https://doi.org/10.1142/s0218843004000973

[43] Free Dictionary. [Online]. Available: http://www.thefreedictionary.com/

[44] M. Weske, "Business Process Management: Concepts, Languages, Architectures," Springer, Heidelberg, 2012.

[45]R.-H. Eid-Sabbagh, R. Dijkman and M. Weske, "Business Process Architecture: Use and Correctness," in Business Process Management, Springer: Heidelberg, pp. 65-81, 2012. Available: http://dx.doi.org/10.1007/978-3-642-32885-5_5

[46]K. Swenson, "The Difference Between Workflow and BPR." [Online]. Available: http://www.e-workflow.org/downloads/workflow-bpr_kswenson.pdf

[47] G. McLeod, "The Difference between Process Architecture and Process Modeling/Design (and why you should care)." [Online]. Available: http://grahammcleod.typepad.com/files/ processarchitecturevsprocessmodelingmcleod.pdf 
[48] D. van Nuffel and M. de Backer, "Multi-Abstraction Layered Business Process Modeling," in Computers in Industry, vol. 63, no. 2, pp.131-147, 2012. Available: http://dx.doi.org/10.1016/j.compind.2011.12.001

[49] G.M. Giaglis, "A Taxonomy of Business Process Modeling and Information Systems Modeling Techniques," in International Journal of Flexible Manufacturing Systems, vol. 13, no. 2, pp. 209-228, 2001. Available: http://dx.doi.org/10.1023/A:1011139719773

[50] B. Curtis, M.I. Kellner and J. Over, "Process Modeling," in Communications of the ACM - Special issue on analysis and modeling in software development, vol. 35, no. 9, pp. 75-90, 1992.

[51] J. de Lara, E. Guerra and J.S. Cuadrado, "Reusable Abstractions For Modeling Languages," in Information Systems, vol. 38, no. 8, pp. 1128-1149, 2013. [Online]. Available: http://dx.doi.org/10.1016/j.is.2013.06.001

[52] J.A. Zachman, "Excerpted from the Zachman Framework: A Primer for Enterprise Engineering and Manufacturing," 2003. [Online]. Available: https://www.thelibrarybook.net/view.php? res=http://www.businessrulesgroup.org/BRWG_RFI/ZachmanBookRFIextract.pdf\&keyword=The+ Zachman+Framework+For+Enterprise+Architecture\%3A+Primer

[53] Archimate. [Online]. Available: http://www.opengroup.org/aboutus

[54] APQC, APQC's Process Classification Framework. [Online]. Available: https://www.apqc.org/pcf

[55] D. van Nuffel and M. de Backer, "Multi-Abstraction Layered Business Process Modeling," in Computers in Industry, vol. 63, no. 2, pp. 131-147, 2012. [Online]. Available: http://dx.doi.org/10.1016/j.compind.2011.12.001

[56] A. Osterwalder and Y. Pigneur, "Business Model Generation," 2009. [Online]. Available: http://www.businessmodelgeneration.com/book

[57] Graham McLeod, The Difference Between Process Architecture and Process Modeling/Design (and why you should care). [Online]. Available: http:/grahammcleod.typepad.com/files/ processarchitecturevsprocessmodelingmcleod.pdf

[58] B. de Bruin, A. Verschut and E. Wierstra, "Systematic Analysis Of Business Processes," in Knowledge and Process Management, vol. 7, no. 2, pp. 87-96, 2000. [Online]. Available: http://dx.doi.org/10.1002/1099-1441(200004/06)7:2<87::aid-kpm71>3.0.co;2-4

[59] J. Grundspenkis and A. Anohina, "Comparison Of Techniques For Business Process Modeling," in Applied Computer Systems - 2nd thematic issue, RTU, Riga, 2001.

[60] L. Businska and M. Kirikova, "The Goal-based Selection of the Business Process Modeling Language," to be published in the Proceedings of the 9th IFIP WG 8.1 Working Conference on The Practice of Enterprise Modeling, by Springer. Available: http://dx.doi.org/10.1007/978-3-319-48393-1_22

[61] L. Businska and M. Kirikova, "The Formalization of the Business Process Modeling Goal: Extended Abstract," B. Johansson, F. Vencovský, Eds., Joint Proceedings of the BIR 2016 Workshops and Doctoral Consortium co-located with 15th International Conference on Perspectives in Business Informatics Research (BIR 2016), Prague, Czech Republic, September 14-16, 2016. [Online]. Available: http://ceur-ws.org/Vol-1684/paper16.pdf 